\title{
"QUAL A RELEVÂNCIA DE UMA DISSERTAÇÃO SOBRE 80 PESSOAS?": DESAFIOS DA PESQUISA INDÍGENA NO DIREITO
}

\author{
JOÃO VITOR DE FREITAS MOREIRA ${ }^{1}$ \\ UFMG, BRASIL \\ https://orcid.org/0000-0002-8508-7699
}

\begin{abstract}
RESUMO: $O$ presente texto tem como objetivo desnaturalizar os pressupostos constitutivos sobre o índio no ponto de vista dos sujeitos do direito. Para tanto, utilizo-me de um episódio reconstruido para revelar categorias que operam consciente e inconscientemente na forma de pensar do jurista tradicional quando tratamos do indio. Por fim, concluo sobre os impasses impostos às pesquisas empíricas de cunho etnográfico desenvolvidas no campo jurídico que busquem colocar em cena os indígenas dessa terra e os desafios éticos que encontraremos ao "estar aqui".
\end{abstract}

PALAVRAS-CHAVE: Índios, Direito, Antropologia jurídica, ontologia, reducionismo

ABSTRACT: The present text aims to denaturalize the constitutive assumptions of the subjects of law when it comes to discussion question about indigenous people. To this end, I rebuild an episode to reveal categories that operates consciously and unconsciously in the traditional jurist's way of thinking when dealing with the Indian. Finally, I conclude about the impasses imposed on empirical research of an ethnographic nature developed in the legal field that seek to put on the scene the indigenous people, and the ethical challenges that we will encounter when "being here".

KEYWORDS: Indigenous people, Law, Legal anthropology, Ontologies, Reductionism

1 Doutorando em Antropologia do Direito pela Universidade Federal de Minas Gerais. E-mail: joaovitorfmoreira@gmail.com. 


\section{Introdução}

O dia era 23 de abril de 2018. Iniciava o curso de mestrado no Programa de pós-graduação em Direito da UFMG, onde ingressei de forma peculiar. Digo isso, pois havia iniciado o curso quase um mês após o início das aulas, já que tinha sido classificado pelo remanejamento de vagas requerido pela banca examinadora. Igualmente, o fato a seguir, que veio a se tornar um dado de pesquisa, caracterizará ainda mais essa peculiaridade, uma vez que antecipava em muito a necessidade de pensar sobre o "objeto" de investigação das minhas incursões etnográficas e pesquisas que pautam relações ameríndias e o campo do direito. A narrativa do fato abaixo funciona, antes de tudo, como algo assemelhado ao que Marylin Strathern (2014) chamou de "momento etnográfico" e que aqui serviu para "marcar" minha trajetória acadêmica, para o bem ou para o mal. O "momento da análise", que agora proponho, só é possível com o "momento da observação", que contêm um dinamismo incrível e por isso descrevo os fatos que busco analisar.

Hesitei em pensar sobre esse episódio que logo tratarei de relatar. Digo isso porque só algum tempo depois fui entender, com Mariza Peirano (2014), que não existe um "momento" muito certo para ativar o olhar antropológico. A informação trazida estava caracterizada no diário pessoal que mantenho como forma de registro das minhas perspectivas e memórias, e não propriamente em um "diário de campo" como dado etnográfico; nem muito menos, ao tempo que anotei, saberia que isso, de alguma forma ou de outra, estava diretamente ligado à pesquisa que desenvolvi naquele Programa de pós-graduação. Hoje, percebo a importância de expressá-lo para além de uma estilística textual.

Era a segunda aula que frequentava de um curso ministrado por dois professores que nomearei de Kraí e $A w i n^{2}$. O curso versava sobre a filosofia da ilustração. Um fato interessante é que um dos professores tinha, digamos, uma "fama" nos contornos da Faculdade de Direito e Ciências do Estado da UFMG, especialmente pela sua forma pujante de interlocução com as pessoas. Após a primeira aula que assisti, na qual me apresentei com nome e sobrenome, isto é, falei quem era a minha orientadora e qual era meu projeto de pesquisa, as coisas pareciam se suceder no curso "natural": um estranhamento contínuo de tudo aquilo que não me era familiar, já que não integrava o quadro de alunos egressos daquela instituição. Logo na segunda aula, marcada pelas exaltações de voz e corpo, caminhava para a porta de saída da sala de aula no $12^{\circ}$ andar do edifício da pós-graduação, quando algo bastante inusitado veio a acontecer. Awin - que se sentava sempre na adjacência à mesa central ao lado da porta de saída - segurou no meu braço e disse: "que que você está pesquisando mesmo?". Bom, recordo que achei bastante estranho aquele tipo de questionamento que interrompeu um fluxo contínuo de saída da sala de aula. Acredito que, inconscientemente, a pergunta feita de forma quase inquisitorial já estava respondida quando Awin, logo na primeira

\footnotetext{
${ }^{2}$ Os nomes verdadeiros foram substituídos por questões de ética em pesquisa. Os dois nomes utilizados têm inspiração na etnologia americanista.
} 
aula que frequentei, perguntava acerca do meu nome e sobrenome. Sem entender muito bem, lá fui dar início à exposição de palavras que aprendi a concatenar para explicar um projeto de pesquisa que já não se apresentava o mesmo na minha cabeça. Afirmei para ele, ainda bastante inseguro, que buscava entender o modo como o direito se comportava em relação ao povo indígena Borum, especialmente após o desastre-crime de Mariana em 5 de novembro de 2015.

A pergunta feita em seguida foi: "quantas pessoas têm lá?". Lembro claramente que retruquei com: "você diz quantas pessoas têm o povo Krenak?". Essa pergunta foi respondida com a anuência não verbal que esperava uma resposta que eu não tinha. Não fazia ideia de quantos indígenas estavam entre as famílias daquele povo indígena. Nunca tinha me ocorrido a necessidade de saber o número certo de pessoas, mas eu rapidamente pensei, enquanto as primeiras palavras saíam, que uma reposta sobre meu desconhecimento deixaria Awin com um desapontamento muito grande. Então, soltei um número, de 80-100 pessoas, dizendo a clássica métrica: "olha, não sei ao certo, mas acredito que...".

A pergunta que se sucedeu foi: "Qual é a relevância de uma dissertação de mestrado sobre 80 pessoas?"

Talvez, essa pergunta tenha sido ainda mais desestruturante que a segunda. Não consegui afastar o gaguejo, mas por sorte emendei algumas palavras, sem muito controle, e que desembocavam na ideia de que perspectivas diferentes das formas oficiais do direito podem ter grande relevância para que algo mais possa ser feito; ainda mais quando o assunto era a questão indígena, populações marcadas por grandes violações. Ao perceber o descontentamento que temia expresso nas feições do meu interlocutor, acabei trazendo as interpretações sobre o direito para além do Estado enquanto um fenômeno muito mais complexo do que uma determinada lei. Recorri à antropologia política de Pierre Clastres para fundamentar que a complexidade das populações indígenas pode se colocar, inclusive, contra o Estado ou a forma de "Um" - tomei a liberdade de soltar essa expressão, pois após alguns anos de estudo, tinha um certo "domínio" de alguns significados na filosofia de Hegel e meu interlocutor era um "especialista".

Entretanto, esse talvez tenha sido o ponto ápice da questão. Só me dei conta tempos depois que dialogar com um ortodoxo é bastante difícil quando se traz algo que está em oposição, pelo menos aparente, às bases de um entendimento de mundo. O meu interlocutor já não era mais interlocutor e disparava ofensas ao mencionado autor como "anarquista de merda...", e outras coisas do gênero que prefiro deixar de lado. Nesse momento, ele começou a fazer uso do mito da brasilidade do Raymundo Faoro e dizia sobre um plano integracionista baseado na figura do Estado e que sem ele não teríamos formas de pensar ou nos organizar.

Tentei argumentar dizendo que isso gera um processo de homogeneização de uma diversidade que é extremamente violento. $O$ Estado, seja qual for, não pode se revelar como uma figura pasteurizante da vida cotidiana. Mas tudo era sem muito sucesso, pois não conseguia concluir ou desenvolver qualquer raciocínio que era cortado no ato. 
Parece mesmo que citar Pierre Clastres foi um erro, já que havia despertado em Awin um fechamento ao diálogo muito grande. Nesse momento, me dei conta que já não havia pessoas na sala. A bem da verdade, existia somente um menino que percebi ser orientando de Awin, enquanto tentava pensar em algo para contrargumentar e acalmar o meu interlocutor que continuava a falar.

Fiz uso das disposições constitucionais do art. 231, dizendo assim: "você pode até não gostar da perspectiva que apresentei, mas você tem que entender que isso decorre de uma garantia constitucional que estabelece um dever do Estado de respeito. Respeito às formas tradicionais de vida". Sim, esse é uma daqueles argumentos de defesa típicos de embates acadêmicos que todos nós temos guardado, por isso bem estruturado.

Em sequência, ele disse: "Mas é claro, podem falar a língua, podem existir lá na aldeia, mas têm que aprender o português, ir à escola... isso também está na Constituição". Dei-me conta, pela forma de enunciar de Awin - infelizmente o texto aqui não é capaz de reproduzir - que falávamos de coisas totalmente distintas ou de perspectivas diferentes.

Então, disse a Awin: "professor, acredito que nós partimos de pressupostos diferentes, então eu preciso saber o que você pensa sobre índio, ou o que é índio? Por exemplo, você acha que pode ter índio na cidade?". Ele hesitou por um segundo e disse: "não, ele precisa estar na terra dele, na sua tradicionalidade. Olha só, eu respeito isso, inclusive sou um dos poucos professores nessa Casa que tem um totem no gabinete, pode ir lá ver!".

Entramos em um ponto que atenuou nossas diferenças. Disse para ele que eu partia de outra perspectiva e que não tinha o mesmo ponto de vista sobre a 'tradicionalidade' e acreditava mesmo que as formas de vida indígenas não são imutáveis, como sua fala aparentava estruturar.

Comecei a falar sobre Eduardo Viveiros de Castro para justificar o porquê usava tanto a palavra perspectiva - e ele assentiu afirmando: "eu gosto dessa palavra". Invoquei uma passagem d'o nativo relativo para mostrar para ele a importância do conceito do nativo, mas também não obtive grande sucesso. Com os ânimos um pouco amornados, lembro dele tentar desenhar uma ideia no papel que opunha "brasilidade" a um conceito que ele acreditava buscar criar sobre "indianidade", mas já me sentia perdido na discussão. Percebi que nada produtivo sairia dali e, por sorte, um grupo de alunos chegou na sala para ensaiar com uma pessoa que estaria prestando o concurso para professor em uma universidade pública. Aí vi a oportunidade de ir embora e logo me despedi enquanto as atenções de Awin mudavam. Ao sair da sala no $12^{\circ}$ andar daquele prédio, percebi que com esse embaraço se foram quase $1 \mathrm{~h}$ e 30 minutos.

\section{A Casa de Afonso Pena e um tema de pesquisa no direito}

O episódio narrado acima poderia, evidentemente, suscitar inúmeras discussões sobre ética profissional, assédio, uma certa arrogância acadêmica de ambos os lados, etc. Entretanto, inicio minhas 
análises de forma a estabilizar alguns pontos para os dados e discussões que apresentarei adiante, pois mais do que o being there (GEERTZ, 1988), esse episódio me forçou a pensar sobre as bases de uma primeira etapa de pesquisa que consiste no being here.

O "estar aqui" não me remete ao seus contermos teóricos clássicos daquele último capítulo no qual Geertz (1988) afirma ser o meio entre os acadêmicos que produz a leitura, o debate e a menção ao tipo de antropologia praticada através das experiências de campo. É, se me for permitido a tentativa de ressignificação, estar inserido em um programa de pós-graduação em direito, ou melhor: o mais antigo programa de pósgraduação em direito do país, que toma lugar na exaltada "Casa de Afonso Pena", às vezes também nomeada como "Vetusta Casa de Afonso Pena". Essa denominação, que é constantemente vista e ouvida nos corredores e além muros, diz algo sobre uma característica que claramente me faltava no episódio descrito. Não participava dessa relação ou simbolização que se construiu sobre a Faculdade de Direito e Ciência do Estado (FDCE); era um total estranho no ninho e Awin sabia disso. Ser estranho aqui é mais do que simplesmente não compor o quadro de alunos egressos da graduação que logo adentram ao programa de pósgraduação, exigia que eu me apresentasse e dissesse o que eu estou fazendo "aqui" para ser julgado como relevantemente interessante à Casa de Afonso Pena. Isso, mais do que um ressentimento, certamente diz também sobre o tipo de assunto que pode entrar nessa Casa; que se pode falar sentado à "mesa" comum de uma sala de aula do $12^{\circ}$ andar. Quando meu interlocutor invocou em nosso em(de)bate a construção "nessa casa", não tinha qualquer reflexão desenvolvida sobre todos os possíveis significados que essa simbolização carregava.

Claro que isso nada tem a ver com relevância científica, está ligado a uma questão que Tiago Nascimento ressaltou em sua etnografia da FDCE, isto é: "o que pude perceber na medida em que avançava na pesquisa foi que mais do que um apelido ou uma metáfora, o familismo sugerido pela ideia de 'Casa' é uma prática recorrente em toda a sua trajetória." (NASCIMENTO, 2017, p. 136).

Não "estar aqui", e assim não compor esse familismo, simplesmente me impediu de conhecer as regras não escritas do funcionamento dessa Casa, de saber quem são as pessoas que animam esses muros e integram (ou integrarão) o Panteão dos Sábios ${ }^{3}$. Acabei, portanto, cometendo gafes que me deixavam ressentido de falar sobre o assunto que buscava pesquisar, que colocavam em dúvida a pertinência de levar à cabo um projeto de pesquisa que trate dos Borum. E, talvez, Awin materializava a grande figura do protetor da Casa, que elege as possibilidades do estar nos espaços percorridos por todos os seus "parentes predecessores". Se levarmos em conta o eixo principal das pesquisas desenvolvidas aqui, claramente percebemos um espaço de produção dogmática e filosófica, com grandes representantes no campo jurídico nacional e por onde

\footnotetext{
${ }^{3}$ Panteão dos Sábios é a denominação que se dá ao $2^{\circ}$ andar que integra os três prédios da FDCE. Sempre muito limpo, composto de pedras brancas e de iluminação constante, o saguão abriga bustos de figuras de grande relevância, todos homens brancos, que se destacaram como professores ou foram relevantes, como foi o fundador Afonso Pena.
} 
"passaram alguns dos mais importantes líderes e juristas da história do Brasil" (WERNECK, 2012, sem paginação). E isso não é uma representação puramente jornalística, de fato compõe o ponto de vista também dos professores e das professoras, como é ressaltado por entrevista concedida ao jornal Estado de Minas por uma docente na data comemorativa dos 120 anos da FDCE: "não há qualquer grande doutrina acerca da democracia, dos limites da autoridade, dos direitos e da política que tenha sido desenvolvida e se imposto em território brasileiro sem sofrer influência da comunidade de juristas, docentes e discentes da Faculdade de Direito da UFMG" (WERNECK, 2012, sem paginação).

Se é um preciosismo típico do "senso comum teórico dos juristas" (WARAT, 1982), não tenho dados para afirmar. Entretanto, quando Awin invoca a denominação "casa", ele traz uma ideia estruturada na continuidade que eu não compunha. Nascimento (2017) faz constar que a entrada na FDCE, muitas vezes, representa uma continuidade na vida dos alunos de graduação, não somente continuidade de classe, cor de pele e trajetória social, "mas em alguns casos representava uma continuidade na convivência com pessoas do próprio círculo pessoal de amizades" (p. 125). O que estou tentando demonstrar com essas primeiras palavras é que a continuidade se prolonga no campo da pósgraduação. A continuidade de um familismo que me via como estranho e condiciona um "estar aqui" passível de discutir determinados assuntos eleitos como dignos de serem tratados no agradável ambiente que é a FDCE.

Essa ideia de agradabilidade, típica de nosso imaginário quando pensamos em nossas casas, é esforçadamente levada a sério, pelo menos na construção da história oficial da FDCE e em suas datas comemorativas. Isso foi patentemente presente no evento de comemoração dos 60 anos da Divisão de Assistência Judicial $(\mathrm{DAJ})^{4}$, quando inúmeros professores estavam sentados nas grandes cadeiras, com nomes de antigos e "brilhantes" professores talhados à mão, e contavam histórias e estórias da "época deles". O ponto mais relevante, e que fiz questão de anotar na minha agenda, foi quando um atual professor e ex-aluno ${ }^{5}$ contava sua história de quando atuava na DAJ. O professor fez questão de dizer que poderia falar sobre os bastidores de um caso, pois as pessoas envolvidas, e que ali estavam presentes compondo a mesa como atuais professores, ele já as conhecia "desde o jardim, estudamos juntos no Loyola". Terminou o caso com uma afirmação que levou todos ao riso, mas que aqui confirma poderosamente os estudos de Tiago Nascimento: "somos todos uma família, uma grande máfia".

Ou, para ser mais "atual", remeto ao discurso de formatura proferido em prosa por dois alunos na noite do dia 06 de dezembro de

\footnotetext{
${ }^{4}$ A Divisão de Assistência Judicial é um espaço de prática jurídica pro bono no qual os alunos e alunas da Faculdade de Direito podem atuar em processos de resoluções de conflitos (judiciais e não judiciais) sob orientação de advogados tutores. Em outros espaços, esse tipo de atividade gratuitamente prestadas pela Faculdade de Direito ganha o nome de Núcleo de Prática Jurídica, Escritório Escola, Escritório Modelo, etc.

${ }^{5} \mathrm{E}$ me parece que essa forma de apresentação “atual professor e ex-aluno” é bastante comum por aqui.

${ }^{6} \mathrm{O}$ Colégio Loyola é uma instituição de ensino privada em Belo Horizonte-MG.
} 
2018. Claro, o espaço festivo sugere o uso de adjetivos que acompanham os agradecimentos gerais. Todavia, o interessante é observar o modo como os alunos se apresentam às inúmeras pessoas que assistiam e que são "de fora" da FDCE. A prosa tomou lugar para dizer:
A: Pode ser, compadre. Mas sabe onde começaram esse caminho que agora estão cumprindo com pesar?
G: Onde é que foi, senhor?
A: Em uma casa muito antiga, de um tal senhor da Pena.
G: Seria a vetusta casa de Afonso Pena?
A: Essa mesma, meu senhor. Pois Afonso que não saiba o que ocorreu à sua casa.
G: Com as paredes, o senhor diz?
A: Não, compadre! Por acaso é de paredes que se faz uma casa?
G: Não, senhor. Uma casa se faz com esmero... e só com ele.
[...]
A: E que retornem, senhor! Pois aquela casa transforma a vida de uma pessoa. Não há como dela sair sem ter experimentado algo de política e algo de direito. Todos os dias, pelo tempo, que ainda corre em outra dimensão, cruzam seus pátios e conversam em seus corredores os sábios que nos ensinaram o que fazer e, sobretudo, não fazer. No tempo de hoje, são só ideia, mas vivem, como também nós viveremos, como também nós vivemos, aquele sonho republicano de 1892 (MAIA; PONTES, 2018, sem paginação).

Isso tudo pode parecer bastante contraditório e parece nada relacionado a temática de pesquisa, especialmente porque o episódio narrado demonstra, por mais que singular, uma controvérsia que não é nada "agradável". Pelo menos, esses traços que configuram as formas oficiais de apresentar a FDCE deixam a

\begin{abstract}
impressão [de] que a história da faculdade é a história de um ambiente quase sempre agradável, praticamente sem conflitos, no qual se formaram muitas pessoas importantes e geniais, às quais, tendo sempre em mente o grandioso legado de Afonso Pena, formaram pessoas igualmente importantes e geniais, garantindo que a Casa, no futuro, não terá outro destino senão ser o que foi e é, uma das mais importantes instituições de ensino de Direito do Brasil. (NASCIMENTO, 2017, p. 97)
\end{abstract}

Essa aparente contradição, na verdade, é devido à parte de que sou parte, ou seja: ela somente aparece de forma não oficial e para alguns sujeitos. Mas por que estou ressaltando esse ponto? Os mais "críticos", certamente serão capazes de lembrar inúmeras disputas e conflitos existentes na FDCE que ganharam repercussão na comunidade acadêmica e fora dela, lembrarão de grupos de estudo que envolviam direitos 
indígenas conduzidos por uma civilista ou até dirão: "aqui se pesquisa até marxismo, direito e música". O interessante é que nunca serão capazes de compreender o imediato estado de defesa que acionam ao se desvelar os significados de sua instituição familiar. Entretanto, nada desses grandes conflitos ou dissensos compõe o símbolo do direito aqui praticado, pois até mesmo as pichações nas salas de aula, que foram alvo de destaque da etnografia de Tiago Nascimento, agora não mais existem devido a uma demão de tinta bege. A continuidade do familismo é capaz de apagar todos os conflitos, atuais e os "de antigamente", para no final "sermos todos uma família", no sentido próprio que a metáfora nos leva a pensar, isto é: assim como no espaço familiar, conflitos existem, mas podem ser superados pela aceitação da ideia de conforto, amor, esmero e agradabilidade que estar aqui" pode proporcionar.

Como desdobramento desse argumento, posso afirmar que trazer ao espaço oficial assuntos que versem sobre idealismo, um pouco de Hegel; modelos kantianos; teorias baseadas em Rawls; justiça tributária; aplicabilidade da vinculação das Demandas Repetitivas no processo civil contemporâneo; violações à Constituição Federal pela condução coercitiva etc., tudo isso, provavelmente, não enfrentaria a pergunta: "qual a relevância de uma dissertação sobre...". Isso, evidentemente, não significa que elas não enfrentarão problemas de legitimação, mais isso se deve a outro problema. Há algo mais complexo no episódio e que requer uma análise mais acurada, apontando não somente para uma deslegitimidade de pessoa, mas de assunto e que certamente trará interessantes proposituras para estranharmos o familiar "estando aqui".

Certamente, as produções científicas são focalizadas, existindo instituições ou pessoas que representam um determinado ponto referencial de estudo. É o caso, por exemplo, do uso da Immanente Kritik no Institut für Sozialforschung; da cultural anthropology americana; dos estudos em antropologia social e etnologia ameríndia desenvolvidos no Museu Nacional; das investigações do Núcleo de Antropologia Jurídica da Universidade de São Paulo. Não é sobre essa ordem de funcionamento acadêmica que estou buscando tratar, mas de uma construção simbólica que leva a fazer a pergunta sem resposta: $O$ quê e quem define essa relevância? Por isso reflito sobre o "estar aqui", uma vez que antes mesmo de produzir o trabalho de campo, sou compelido a justificá-lo e buscar sua pertinência em um espaço que diz muito sobre as vertentes da produção sobre o direito no Brasil, revelando uma relação conflituosa não somente sobre a pessoa, mas sobre o assunto a ser tratado.

Certamente, a temática indígena não é muito próxima dessa casa. E isso é facilmente verificável se adentrarmos a uma análise das publicações, projetos e orientações desenvolvidas pelas pessoas que compõem a pós-graduação. Atentando para as produções científicas nos currículos disponíveis na plataforma lattes dos 67 professores e professoras integrantes do corpo permanente ${ }^{7}$, podemos notar essa evidência. Ao fazermos uma análise detida buscando as palavras-chave

Informação verificável no site do Programa de pós-graduação. Disponível em: https://pos.direito.ufmg.br/?page id=1937. Acesso em 05 fev. 2019. 
índio, indígena, povos tradicionais e comunidades tradicionais nos currículos públicos, encontraremos o seguinte resultado:

Gráfico 1 - Professores do corpo permanente do programa de pós graduação em Direito da UFMG com atuações na temática indígena

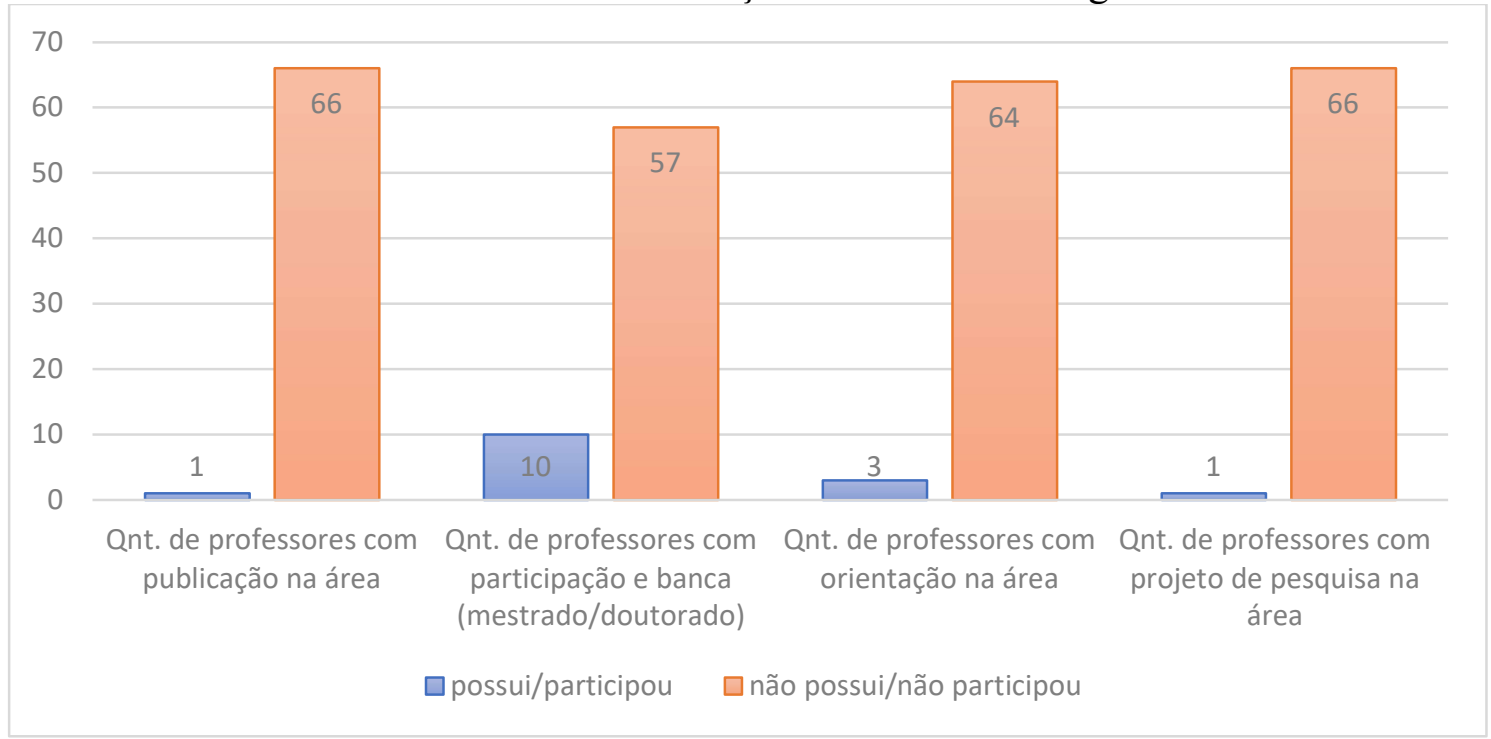

Fonte: o autor.

Esses dados, eminentemente quantitativos, corroboram com o caráter do argumento apresentado, pois acabam por revelar a estrutura do comportamento institucional das pessoas envolvidas na produção e ensino acadêmico. Revela, outrossim, a face pragmática do habitus ${ }^{8}$ da FDCE.

Contudo, entendo que não é somente o familismo representado pela ideia de casa que condiciona a possibilidade de fala, mas também devido à grande disputa sobre o ser índio nos debates contemporâneos. Penso que as catracas presentes no rol do edifício Villas Boas, n 100, não selecionam e autorizam somente as pessoas que circulam pelos prédios, dizendo quem pode e não pode entrar. Em similitude com as análises feitas sobre a "briga de galos" (GEERTZ, 1973)9 , as catracas que se encontram dispostas no rol de entrada movimentam pessoas, clãs ${ }^{10} \mathrm{e}$ assuntos de pesquisa: alguns podem entrar fisicamente, outros assuntos carecem de muitos esforços para produzir modificações simbólicas na imagem que é construída e exaltada na FDCE. A dissimilitude nessa comparação é que essas regras muito rígidas não estão escritas em folhas de palmeiras (GEERTZ, 1973, p. 418).

Desse modo, não deixo de ser um estranho que bate à porta para tratar de um assunto impróprio. Mas a questão não é somente o que pode

\footnotetext{
${ }^{8}$ Ao empregar o termo não quero aqui trazer toda a sociologia de Bourdieu, em especial o famoso capítulo sobre o poder simbólico do direito. Isso seria deslocar o foco local para uma análise global. Se há algo em especial nas posturas contemporâneas da antropologia é justamente a necessidade de situarmos os saberes produzidos (HARAWAY, 1995).

${ }^{9}$ Refiro-me a esse fato, uma vez que Geertz (1973) demonstra que: "for it is only apparently cocks that are fighting there. Actually, it is men" (pag. 417).

${ }^{10}$ Uso esse termo não somente por um recurso de linguagem, mas uma família de professores ganha essa denominação pelas pessoas que frequentam a FDCE.
} 
ser tratado aqui, pois se não há uma doutrina jurídica, política ou democrática que não tenha sofrido a influência de discentes e docentes da FDCE, parece-me que o assunto que trago não tem relevância às grandes construções sobre o direito. Se em tempos de outrora caracterizou-se, com a Constituição de 1988, o renascer dos povos indígenas para o direito (SOUZA FILHO, 1998), nessa "casa" as formas jurídicas praticadas são imiscíveis aos debates antropológicos sobre indígenas. E isso, em grande medida, perpassa pela reprodução de uma imagem de índio claramente invocada no episódio acima, uma relação ontológica de como deve ser índio já disposta em seu negativo.

Isso não se trata de um "comportamento" isolado, pois a temática indígena não é muito afeita às instituições que têm como foco a filosofia e o direito. Além do mais, ter uma erudição, um título acadêmico em ciências humanas ou um acúmulo de compreensão sobre determinado assunto não nos torna mais sensíveis a uma temática, pois ao final acabamos sempre como "connoisseur of case in point" (GEERTZ, 1983). A grande questão é que em áreas do conhecimento cuja relação é de encontros e desencontros cosmológicos constantes, como caracterizarei a relação entre o direito e os Borum, não basta apenas sermos conhecedores pontuais. O desafio é maior para ambos.

\section{Índio ou Indígena: o desvelamento de um pressuposto duplamente negativa"1}

Nós, grandes classificadores práticos do mundo, somos capazes de ordenar tudo e todos num plano ontológico muito bem definido, seja qual for o "modelo". Os questionamentos sobre o ser - uma das mais difíceis perguntas da filosofia - encontram significados muito acentuados quando observamos a realidade empírica dos diversos "grupos formadores da sociedade" (tal como escrito na Constituição) e que compõem o imaginário dos reprodutores do grande mito da brasilidade. Ou, se nos voltarmos novamente ao em(de)bate, parece-me existir um significado muito bem estruturado do que é índio no ponto de vista do meu interlocutor, mas que somente a filosofia com pessoas dentro (INGOLD, 1992, p. 696) é capaz de mostrar.

Esse significado se revela aos poucos e tem desdobramentos interessantes, pois acredito que resguarda uma negação de categoria em sentido duplo e tem reflexos futuros. Um deixar de ser índio para se tornar cidadão brasileiro falante de português - o que requer uma ascensão ao estatuto tão almejado por nós de sujeitos de direito. E isto está muito bem disposto quando meu interlocutor invoca em sua fala a necessidade de aprender a língua portuguesa, pois é essa que todo cidadão brasileiro fala. Mas antes de chegar lá, existe um percurso muito certo a se seguir, cujo leitmotiv é associar o ser indígena a imagens estáticas e simplórias quanto aos seus significados. Digo isso, pois, como a literatura etnológica já demonstrou (CARNEIRO DA CUNHA, 1990, 1992)

\footnotetext{
${ }^{11} \mathrm{O}$ duplo negativo aqui, diferente das ciências da natureza, não implica o positivo.
} 
a formação do imaginário brasileiro sobre o índio é basicamente constituída das representações etnocêntricas que os povos europeus tinham sobre os povos americanos, a partir de um primeiro olhar que se reduz às fronteiras que 0 Tratado de Tordesilhas permitia aos portugueses construírem. Portanto, as representações que ainda persistem são "duas imagens de índios que só muito tenuamente se recobrem: a francesa que o exalta, e a ibérica, que o deprecia. Uma imagem de viajante, outra de colono" (CARNEIRO DA CUNHA, 1990, p. 109). Porém, creio que essas ditas imagens representam na verdade uma forma predisposta acerca do que existe, um negativo que dispõe a condição de existência e que, suspeito, ainda permanece em algumas categorias jurídicas ou nos raciocínios dos sujeitos de direito por excelência.

De qualquer forma, essas representações ou imagens do ser índio também não são apresentadas sem grandes modulações na literatura. Do bom selvagem que P. V. Caminha relata, passando pelo índio antropófago colonial ocupante de uma primitividade ingênua, até chegar ao índio cuja capacidade de falar é negada (GRAHAM, 2011): todas essas ideias são mais ou menos a essencialização do ser índio como um ente sem fé, sem lei e sem rei. Ou, qualquer outra variação que essa métrica possa assumir e nos parece que assumiu' ${ }^{12}$ nessa fórmula clássica de uma antiantropologia (e não contra-antropologia). Decerto, hoje parece existir uma essencialização do ser índio como que, na melhor das hipóteses, busca o proteger da grande perversidade que nós Brancos somos capazes produzir. Portanto, o paternalismo sombrio ofusca o exercício de qualquer alteridade, e o máximo que conseguimos alcançar é um relativismo complacente (VIVEIROS DE CASTRO, 2011). E esse relativismo é a maneira mais bem construída e solidamente edificada nas nossas formas ocidentais de pensar e produzir conhecimento, pois é a "maneira de não estar em lugar nenhum, mas alegando-se que se está igualmente em toda parte" (HARAWAY, 1995, p. 23-24).

Veremos, entretanto, como essa medida opera um reducionismo, uma essencialização que nada mais são do que pressupostos tidos como dados nos encontros pragmáticos acerca do ser índio. Uma tarefa difícil. Não basta ser indígena, tem que aparecer índio, ser fotogênico e enquadrar-se numa imagem de índio muito bem caracterizada e que coloque sua tradicionalidade à mostra, mas que aos poucos tem que deixar de ser (tem que aprender o português, diria meu interlocutor). Essa é a ofensiva não anunciada, mas que sempre esteve em curso a partir de uma "guerra silenciosa" - os Borum chamarão de Guerra sem fim $^{13}$,

\footnotetext{
${ }^{12}$ Ainda hoje a filosofia política se preocupa muito com os desdobramentos que essas junções podem assumir. Nunca é tarde para lembrar que mesmo os mais avançados questionamentos sobre as formas morais da pessoa (SPAEMANN, 2006; HONNETH, 2009) perpassam pela aquisição, ou proteção, do status normativo da dignidade, proposta jurídica muito bem estruturada (Lei), cuja origem (TAYLOR, 1994) remonta às formas cristãs (Fé) e tem no Estado o grande garantidor (Rei).

${ }^{13}$ Trata-se de uma forma de explicar as variadas violações sofridas pelos indígenas e que dá nome a um documentário produzido por eles: Guerra Sem Fim. 2016. Direção: Vitor Blotta e Fabrício Bonni. Produção: Ministério Público Federal. Roteiro: Vitor Blotta e Fabrício Bonni. 1 vídeo (29m e 40s). Publicado pelo canal Unnova Produções. Disponível em: https://www.youtube.com/watch?v=DfkGVfkJpAM\&t=858s. Acesso em: 16 abr. 2019.
} 
numa alusão ao decreto de D. João VI - cujo objetivo é uma simplificação ontológica. Mas essa ofensiva não é só contra os índios, ela é contra a proliferação de multiplicidades epistêmicas que muitas das indigeneidades, índias e não-índias, revelam em suas mais complexas formas de pensamento.

É necessária uma distinção: já foi anunciado que "no Brasil, todo mundo é índio, exceto quem não é” (VIVEIROS DE CASTRO, 2008). Então, acredito que aqui o problema se inverte. Não é uma questão com o ser índio, mas com quem não é. E, certamente, os juristas não são indígenas. A grande diferença é que nem todo indígena é índio ${ }^{14}$, até porque ser índio implica uma relação de pertencimento inversa às formas que nós estamos acostumados a lidar. São os índios que pertencem à terra, e não o contrário. Nesse ponto, sou afortunado, pois para entender isso basta observar o significado que uma autodenominação feita pelos Borum nos diz: Krenak é a junção de kren, que significa cabeça, na medida em que associado com nak, que é terra, permite vislumbrar de onde esse povo origina-se (ver PARAíSO, 1992; SOARES, 1992).

Mas não seria justamente isso o que meu interlocutor busca dizer ao colocar que "ele tem que tá na terra dele, na sua tradicionalidade"? Acredito que não. A interposição do significado depende de seu contexto, por isso a localização de espaço feita anteriormente. O ponto de vista expresso naquele episódio marca e define também os sujeitos que pensam o direito, mas não é somente isso. Ele é (re)produtor de uma redução potencial que, não raramente, leva-nos a encontrar grandes questionadores sobre a existência de índios no Brasil e adeptos de uma teoria da mestiçagem (RIBEIRO, 1970), que aponta para uma "mistura" enquanto categoria sociopolítica do Brasil. Essa ideia, que encontra ressonância na cultural traits theory desde Kroeber (HANDLER; LINNEKIN, 1984) e que no Brasil ganhou grande expressão com os estudos de aculturação (BALDUS, 1949; GALVÃO, 1960; RIBEIRO, 1970; SAMPAIOSILVA, 2000), ainda é persistente na formação conceitual do ser índio. Por isso, "um índio calçado e vestindo com calça jeans, falando português, utilizando gravadores e vídeos ou morando em uma favela em São Paulo aparece aos olhos do público como menos índio. Eles deveriam seguir suas tradições, se diz" (COHN, 2001, p. 36).

Um exemplo significativo é o fato de que muito do que se fala sobre povos indígenas atualmente nos remete aos povos do Brasil Central e Setentrional, na medida em que povos indígenas da região Sudeste e Nordeste são facilmente explicados como assimilados pela sociedade, inexistentes portanto ${ }^{15}$. Se buscarmos um importante trabalho de Eduardo

\footnotetext{
${ }^{14}$ Remeto o leitor ao já famoso texto de Eduardo Viveiros de Castro (2017) onde essa distinção é feita. Na verdade, quem realiza essa caracterização na literatura é Cardoso de Oliveira (1993) e Viveiros apenas a atualiza com dados.

${ }^{15}$ Um ponto interessante é trazido por José Maurício Arruti (1997, p. 20): "Nos primeiros documentos do órgão indigenista e nos textos dos primeiros folcloristas/etnólogos sobre os grupos do Nordeste, fica clara a indecisão na escolha da categoria atenuante mais adequada, levando à alternância e combinação de 'caboclo', 'descendentes indígenas', 'remanescentes indígenas' e outras variantes, em que o 'indígena' podia ser substituído por designações étnicas ou toponímicas. Essa indecisão, no entanto, com o tempo, cedeu lugar a um franco predomínio do termo 'remanescentes', categoria que se mantém presente ainda
} 
Galvão sobre áreas culturais do Brasil, encontraremos exatamente a perspectiva de aculturação como um elemento qualificante da dificuldade de lastrear áreas culturais dos povos índios da região Nordeste, sendo eles tidos como integrados no meio regional, "registrando uma considerável mesclagem e perda de elementos culturais tradicionais, inclusive a língua" (GALVÃO, 1960, p 39). A perda da tradicionalidade enquanto distintivo cultural é, ao mesmo tempo, o fim e o início de uma postura ontológica. É o marco enunciado para deixar de ser índio, acionando argumentos da "perda" de uma essencialidade que instantaneamente os tornam outra coisa, mesmo que o ponto referencial dessas classificações seja sempre nosso sobre eles. Essa margem revela que o significado de tradicional é tomado como uma apresentação de traços culturais inerentes não submetidos à forma do devir; que perpetuam uma autonomização simbólica do ser índio que impossibilita a existência de qualquer modo, ou de qualquer outro modo.

Bom, se a firmação "ontologias são o acervo de pressupostos sobre o que existe" (ALMEIDA, 2013, p. 9, destaque no original), o ponto de vista constitutivo do meu interlocutor parece esperar a existência desse índio tradicional a-histórico nunca disposto no tempo presente. Há uma certa invenção - no sentido negativo ${ }^{16}$ - de uma concepção naturalista e romântica do nativo vivendo e compondo a natureza que nunca será autenticamente representado no plano da existência empírica, pois não corresponde a uma realidade de atuação política desenvolvida por muitos povos indígenas na atualidade. Por isso se trata de uma perversa forma de representação do ser índio e propriamente uma redução ontológica das potenciais formas de existir e, talvez seja mais adequado, (re)existir. Uma ontologia minimalista, a-histórica e programática. Mas, como disse um índio Borum: "se é uma guerra sem fim, também é resistência sem fim".

Interessante é observar que trabalhos etnográficos e análises históricas, que tomam o cuidado para não incorrer em anacronismos, desconstroem ou bagunçam as percepções enraizadas nesse símbolo autonomizado do ser índio. O destaque à organização política que manuseia esse símbolo a seu favor, assemelha-se aos contornos de um essencialismo estratégico que busca sanar os conflitos por terra, que ironicamente perpassam por todas as questões indígenas. Os Kaingang do oeste de São Paulo, por exemplo, convivem com grupos de índios Borum que foram deslocados de Minas Gerais para lá durante a ditadura militar, sendo os conflitos interétnicos existentes. No entanto,

[a]s manifestações étnicas estão no cotidiano desses índios, procuram exaltá-las sempre que podem, principalmente quando da presença de estranhos na aldeia. Sabem como são vistos pelos regionais e sabem também como manipular a sua concepção sobre o que é ser índio; em períodos de festas e comemorações que

hoje nos textos e discursos de autores e personagens que, através dela, acabam por criar uma categoria especial de índios e reconhecer um padrão particular de 'indianidade"”

${ }^{16}$ Ver as distinções que Roy Wagner (1981) realiza sobre o termo. 
abrangem toda a aldeia, se organizam para apresentar ao outro sua cultura, exibida através de danças, cantos em Kaingang ou Krenak, pintam-se e vestem-se como "índio". (CRUZ, 2007, p. 114)

Não obstante, os estudos realizados entre os Kaingang do oeste paulista são um exemplo da construção de que índio é membro "de povos e comunidades que têm consciência - seja porque nunca a perdera, seja porque a recobraram - de sua relação histórica com os indígenas que viviam nesta terra antes da chegada dos europeus" (VIVEIROS DE CASTRO, 2017 , p. 187). Essa consciência os coloca a frente de suas próprias histórias feitas no tempo presente, compostas por uma rede de significados que estrategicamente utilizam-se dos conceitos ocidentais e tradicionais.

Mas isso não me parece um ato isolado e singular de um grupo. Os Arara do rio Iriri no estado do Pará, que foram considerados extintos em 1940, ao realizar os rituais da Festa do Jacaré dão importância, como expressão de uma consciência, ao "apresentar-se" para os Brancos:

Trata-se de mostrar a este importante outro o que é ser Arara. Há uma preocupação declarada em se apresentar como índios de verdade frente aos Brancos, ou seja, em executar música e dança tradicional, em se alimentar de comidas que consumiam antes do contato e em ornamentar seus corpos. Todo este processo de "virar índio" é conduzido de uma forma propriamente arara. $\mathrm{E}$, como em qualquer ritual, seus efeitos são, ou buscam ser, transformativos. (OTERO DOS SANTOS, 2014, p.12)

Em uma mesma linha, Berth A. Conklin (1997) endereça o argumento de que na contemporaneidade a identidade política e a imagem corporal se tornam símbolos em zonas de atuação e confronto que se enquadram, corriqueiramente, em demandas sobre a autenticidade dos índios. Apesar das discordâncias contemporâneas acerca dos debates sobre "identidade" na questão indígena, Conklin narra uma situação que tomou lugar na Earth Summit no Rio de Janeiro em junho de 1992:

$[\ldots]$

Confronted with this dilemma, several Kayapó addressed the problem by stationing themselves as self-appointed bouncers at the doors of the conference room to determine who would be admitted. Faced with would-be participants as diverse as Filipino tribal and blond, blueeyed Laplanders, they screened on the basis of appearance: only individuals wearing exotic, apparently non-Western costumes were admitted. Thus, when two North American Indians appeared dressed in street clothes, they were turned away. When the same two individuals returned the following day in beads and 
feathers, they entered without difficulty. (CONKLIN, 1992 , p. 727) ${ }^{17}$

Esses dois exemplos ilustram não somente a centralidade que o corpo assume nas relações ameríndias (SEEGER; DAMATTA; VIVEIROS DE CASTRO, 1979), mas trazem à tona um performar político em torno do símbolo construído pelo ocidente. Acredito que os desdobramentos performativos não se resumem à corporalidade e adentram ao campo dos atos de linguagem, aqui entendidos no modo como os índios falam.

Laura Graham $(2003,2011)$ coloca em evidência que lideranças indígenas e porta-vozes tomam decisões estratégicas sobre o uso da linguagem mixada, que por hora ressalta a tradicionalidade pela escolha de falar muitos termos em idioma nativo. E não é comum encontrar lideranças indígenas que comecem suas falas com cumprimentos tradicionais, ou façam referências diretas à língua, como fez Joênia Wapichana na sua sustentação oral ${ }^{18}$ no Supremo Tribunal Federal no caso da demarcação da Terra indígena Raposa do Sol (BRASIL, 2009); ou como fez Shirley Djukurnã Krenak quando se apresentou a mim na língua borum em uma reunião do Núcleo de Agroecologia de Governador Valadares MG.

De qualquer forma, o desdobramento da perversidade do pressuposto acerca do ser índio também encontra lugar na fala, pois ao optarem por transitar para uma paridade de fala em uma linguagem comum de Estado, inúmeros questionamentos são levantados acerca da "autenticidade" e capacidade representativa da liderança. Kirsch (2014) traz um relevante dado de pesquisa que ilustra esse impasse ao etnografar os contornos da famosa OK Tedi Mine, em Papua-Nova Guiné:

The Yonggom and their neighbors also invoke the discourse of environmentalism and the language of science to convey their concerns about pollution from the Ok Tedi mine, but in doing so, they face a double bind. If they address environmental problems using their own terms and concepts, as when the Yonggom describe the Ok Tedi mine as a corporate sorcerer, they risk being misunderstood and having their views treated as irrelevant to scientific or technocratic decision making (Burton 1997, 41-43). Conversely, people claiming indigenous rights risk having their testimony judged as inauthentic if they use the language of science when

\footnotetext{
17 “Confrontados com este dilema, vários Kayapó abordaram o problema posicionando-se como seguranças autonomeados nas portas da sala de conferências para determinar quem seria admitido. Diante de candidatos a participantes tão diversos como tribos filipinas e lacedores loiros de olhos azuis, eles foram selecionados com base na aparência: apenas indivíduos vestindo trajes exóticos, aparentemente não ocidentais, eram admitidos. Assim, quando dois índios norte-americanos apareceram vestidos com roupas de rua, eles foram rejeitados. Quando os mesmos dois indivíduos voltaram no dia seguinte em contas e penas, entraram sem dificuldade. (CONKLIN, 1992, p. 727, tradução minha).

${ }^{18}$ Disponível em: https://www.youtube.com/watch?v=J46FvCHWsYU. Acesso em: 01 jan. 2019.
} 
speaking about environmental issues $[\ldots]^{\prime \prime} \quad(\mathrm{KIRSCH}$, 2014, p. 81). ${ }^{19}$

Assim, entendo que a reprodução dessa percepção ontológica do ser índio retira do espectro a capacidade de agência indígena ao negar compreender as transformações ou adaptações nos seus conceitos e teorias. Esse último exemplo tem força para colocar esse ponto em questão, porque a capacidade de articulação indígena no caso da OK Tedi Mine foi a principal oposição aos avanços da devastadora mineração da BHP Billinton naquelas terras (KIRSCH, 2014), ao passo que a desvinculação de uma percepção ontológica levou ao próprio Estado da Pápua-Nova Guiné a não reconhecer o povo Yonggom como indígenas (KIRSCH, 2014, p. 209).

Apesar desses exemplos demonstrarem as articulações políticas acerca do símbolo do ser índio (bem como algumas de suas consequências), eles são capazes apenas de evidenciar uma parcela do argumento. Para estruturar a outra, retomo os estudos dos índios do Nordeste brasileiro, que "na década de 50, a relação de povos indígenas do Nordeste incluía dez etnias; quarenta anos depois, em 1994, essa lista montava a 23" (OLIVEIRA FILHO, 1998, p. 47). Índios enrustidos? Brancos que viraram índios? Índios que viraram Brancos e, depois, viraram índios de novo? Essas comunidades emergentes, que causam estranheza até mesmo entre seus defensores, tencionam novamente as percepções sobre o significado de tradicionalidade expresso na imagem geral sobre o ser índio.

A questão é que os "novos" indígenas do Nordeste nunca deixaram de existir. Contudo, ao recobrarem a sua consciência em relação histórica com os indígenas que viviam naquelas terras ${ }^{20}$, de pronto são colocados "à prova", até porque muitos elementos que compunham a diversidade daqueles povos indígenas foram forçosamente proibidos e fisicamente constrangidos pela ascendente figura do Estado. Existe uma ausência de referência ao símbolo geral do ser índio que compõe o imaginário geral de nós classificadores brancos, presente nas designações de áreas culturais indígenas desde Galvão (1960). Por sorte, importantes trabalhos de campo (SAMPAIO, 1986; CARVALHO, 1977; OLIVEIRA FILHO, 1998, 1999) contribuem para uma tentativa de obviação (WAGNER, 1981) desse símbolo:

\footnotetext{
19 “Os Yonggom e seus vizinhos também invocam o discurso do ambientalismo e da linguagem da ciência para transmitir suas preocupações sobre a poluição da mina de Ok Tedi, mas, ao fazê-lo, enfrentam um duplo empecilho. Se eles lidam com problemas ambientais usando seus próprios termos e conceitos, como quando os Yonggom descrevem a mina Ok Tedi como um feiticeiro corporativo, correm o risco de ser mal interpretados e ter suas opiniões consideradas irrelevantes para a tomada de decisões científicas ou tecnocráticas (Burton 1997, 41-43). Por outro lado, as pessoas que reivindicam direitos indígenas correm o risco de ter seu testemunho julgado como inautêntico se eles usam a linguagem da ciência quando falam sobre questões ambientais [...]" (KIRSCH, 2014, p. 81, tradução minha)

${ }^{20}$ Alguns autores (OLIVERA FILHO, 1999; VIVEIROS DE CASTRO, 2017; BARTOLOMÉ, 2006; LISBOA, 2017) articulam essa retomada devido a um favorecimento no cenário antropológico, com um despertar do interesse acadêmico, e jurídico, principalmente por conta da ascensão das garantias constitucionais que as lutas e articulações indígenas levaram a compor o corpo do art. 231 e 231 (BRASIL, 1988).
} 
A referência à ausência de "certa compreensão, explicação" para justificar o desconhecimento da identidade genérica índio continua por nós sendo percebida como a ausência formal do elemento relacionai dominante, responsável pela sua atribuição. Quando o elemento relacionai se faz presente, eles não mais se designam como caboclos (caboclos de Barra Velha, conforme a maioria), classificador regional, mas como índios, e índios a quem se atribui uma identidade específica, Pataxó no caso:

'Eu não sabia que era Pataxó. Vim saber que nós era Pataxó da chegada desse chefe nosso [primeiro chefe do Posto indígena]. Mas o nosso pai não dizia o que nós era ... depois que o chefe chegou foi qüe falou que nós era Pataxó. Aí fiquemo Pataxó toda vida...Acreditamo porque eles falaram, eles conhece índio...'" (CARVALHO, 1984, p 174)

Essas etnogêneses (BARTOLOMÉ, 2006), para ser preciso conceitualmente, produzem novos sujeitos coletivos com lógicas cognitivas que identificam substratos tradicionais em relação às vidas sociais que o cercam com o intuito de assentarem uma diferença que "não se trata de uma continuidade cultural linear, mas de uma continuidade dos significados culturais da experiência” (BARTOLOMÉ, 2006, pag. 59). Essa perspectiva, que poderia soar como uma identificação de uma prática reversa, mostra uma transformação na consciência que os históricos confrontos interétnicos produzem, revelando a capacidade de pensar conceitualmente signos dos mais variados e compor estrategicamente (talvez essa não seja a palavra mais adequada) atuações eminentemente políticas e jurídicas. Então, onde está a tradicionalidade para ser mostrada ao Branco? Ou melhor, qual tradicionalidade deve se mostrar? Isso varia, a depender das demandas internas e externas de uma comunidade tradicional, bem como dos vetores que são acionados não raramente pelo Estado na ofensiva contra seus direitos.

Esse pensar conceitualmente questiona 0 significado de tradicionalidade que ontologicamente construímos ou reproduzimos, mostrando uma "flexibilidade" acerca das classificações que as produções científicas sociais - e militantes alertaria Arruti (1997) - cristalizaram como imperativos acerca das potencialidades de ser e que produzem, hoje conseguimos reconhecer, práticas etnocêntricas e extremamente violentas.

Com essa exemplificação retomo o que disse acima sobre a negação das potencialidades da categoria índio. Foi possível evidenciar que é uma negação na direção de deixar de ser para ocupar uma outra categoria: a cidadão brasileiro, por completo e integrado. Caso não seja possível acionar no imaginário do Branco um índio autêntico, certamente as outras formas de existir índias não são possíveis. Entretanto, isso apenas exemplifica uma versão da ontologia em espaço de direito, a outra é que a única possibilidade de se tornar é não-índio, o contrário é 
impossível. Isto é, a negação ontológica ocorre em um duplo sentido porque afirma pressupostos de uma imagem do ser índio que não encontra correspondentes no plano pragmático - mas que certamente opera na obrigatoriedade de deixar de ser. Assim como produz uma impossibilidade reversa: o voltar a ser índio. Isso soaria como uma grande heresia, ou uma ofensa ao meu interlocutor que seguramente compactuaria com essa impossibilidade. Imagine se tivesse retomado ao em(de)bate com um exemplo acerca da inconstância dos índios "vestidos" de caboclos?

Mas isso não é tudo. Se tanto a "indianidade" quanto a "brasilidade", que meu interlocutor queria rascunhar como conceitos opostos em um pedaço de papel, são formas de uma mesma perspectiva, e que, por mais que tenhamos nos afastado, a questão de dizer quem é o que ainda persiste nessa visão. Mas essa não é uma questão que importuna muito os antropólogos (pelo que me parece), tão somente aos juristas que buscam sempre dizer e separar as pessoas e as coisas sistematicamente para poder, então, classificá-las como relevantes juridicamente. O tipo de conhecimento que produzimos sempre traz, antes de tudo, a pergunta "pra que serve?" (ou "qual a relevância de...?") que resguarda um fundo de utilidade refletido nas formas e pressupostos sobre o que existe (ontologias). Talvez esse seja o problema, não é uma questão com os índios, mas com quem não é. No meu caso, com os produtores do direito.

\section{Conclusão: desnaturalizar os pressupostos}

Em momento algum foge à mente as diversas lutas por reconhecimento que as comunidades indígenas do Brasil desencadearam e desencadeiam na busca por direitos. Faz parte da 'resistência sem fim". Inclusive, minhas incursões empíricas e interlocuções de pesquisa se dão, em grande medida, porque pude corroborar essa tentativa de afirmação de direitos. Muitos desses direitos, narrados como originários (CARNEIRO DA CUNHA, 2012, 2018), derivam de uma positivação constitucional que hoje começamos a entender um pouco mais sobre os seus bastidores (DIAS, CAPIBERIBE, 2019). Não, não se trata somente do importante capítulo do índio, mas de um pressuposto escrito nos artigos 215 e 216 que reconhece realidades múltiplas ${ }^{21}$ estruturantes, mas também estruturadas, sobre o que se designa como sociedade brasileira.

É esse pressuposto, que apresenta uma variedade de possibilidades sobre expressões culturais, que parece faltar aos agentes do direito mesmo porque a possibilidade de mudança inscrita na ideia de "cultura" aqui expressa só se dá quando os próprios atores dessa "cultura" somos nós. Uma relação ontológica centrípeta que coloca em um moinho satânico, para usar uma adequada expressão de Polanyi (2011), as possibilidades epistêmicas mais variadas. No meu caso, a ontologia

\footnotetext{
${ }^{21}$ Uso o termo no sentido de Annemarie Mol (2007, p. 5-6) para configurar uma possibilidade que adentre também ao campo ontológico, uma vez que realidades múltiplas indicam possibilidades de construções alternativas sobre plano da existência e não somente uma pluralidade de pontos de vista sobre o mesmo objeto existente.
} 
minimalista do ser índio como imagem fixa no espaço do direito se apresentou como um impasse epistemológico, que se desdobra em impasses para realização de uma pesquisa de campo. E me parece que esse impasse não é singular. Uma rápida consulta no sistema de bibliotecas da UFMG acerca de trabalhos acadêmicos produzidos na pósgraduação, somados aos dados oficiais dos professores descritos anteriormente, nos permite observar o irrisório número de exemplares sobre esse assunto nos contornos simbólicos da FDCE.

Porém, ao me dar conta de que enunciados sobre o ser índio têm natureza performativa e não constatativa, como tentei demarcar acima, sigo adiante. Mas agora com propósitos que transcendem a uma evidência científica e que se mostram como disputas políticas capazes de modelar as formas de atuar e pensar na academia. Entender a produção de significado por meio das redes de interlocução é um desafio ao estar em campo, assim como ao estar aqui - ou nos espaços oficiais de formação dos juristas e de produção do direito. Espaços esses que podem ou se tornam imiscíveis às discussões sobre o índio, independentemente da existência de preceitos legais em uma constituição que precisamos aprender ler até o fim. Não raramente, quando essa miscibilidade é possível, reproduzimos um relativismo paternalista.

De alguma forma, essa constatação não é nova. A existência de direitos, que normalmente perpassam por lutas por reconhecimento, é algo diferente de sua eficácia. Não por acaso, as demandas por territórios perpassam pela adjudicação do direito em uma instância de resolução oficial, mesmo essa garantia já estando disposta na legislação brasileira desde tempos anteriores à República (CARNEIRO DA CUNHA, 2018). O que é novo é entender que por detrás de um simples desrespeito às formas jurídicas oficiais está uma concepção muito bem estruturada que expõe pressupostos acerca do ser índio a serem preenchidos no campo pragmático. Um espaço sensível e que carece de mais estudos para demonstrar como o símbolo perpetrado pelo direito acerca do ser índio opera no mundo empírico para além de uma eficácia simbólica. $O$ episódio que narro, bem como as ideias de caráter ensaístico que ofertei, apenas podem ser dispostos como hipóteses, afinal, começarei a verificar sua repetição à medida que caminho nas pesquisas. Entretanto, em tempos no qual o avanço do Estado etnocida sobre os índios nunca se mostrou tão voraz, a sensibilidade com o tema que trago se aguça no sentido de operar uma necessária obviação simbólica e proliferar as múltiplas ontologias nos espaços de direito. Talvez, o que seja necessário colocar em suspensão estando aqui seja a supremacia do pensamento ocidental e sujeitá-la à incrível experiência de experimentar outras ontologias, outras epistemologias e, quem sabe, até tecnologias (SZTUTMAN, 2008).

Confesso que as barreiras que acreditava encontrar no desenvolvimento de uma pesquisa em direito seriam distintas, ou qualitativamente diferentes. Contudo, estando aqui, as dimensões simbólica e empírica são outras - ou outros também - e condicionam não só as pessoas que entram na FDCE, mas também os assuntos de pesquisa. Por consequência, representam, em uma pequena medida, a "cultura" 
jurídica sobre determinados assuntos que se colocam à mesa. De outro lado, revela também um conceito de cultura totalmente contrastante com alguns entendimentos na antropologia, do qual prefiro ficar com a ideia de cultura como "estruturações potenciais da experiência, capaz de suportar conteúdos tradicionalmente variados e absorver novos" (VIVEIROS DE CASTRO, 2002a, p. 209). Portanto, é necessário pensar de outra forma, desnaturalizando os pressupostos de uma "ciência" incorporada nos espaços nos quais nos inserimos. 


\section{Referências bibliográficas}

ALMEIDA, Mauro W. Barbosa de. Caipora e outros conflitos ontológicos. Revista de Antropologia da UFSCar, v. 5, n. 1, jan./jun., p. 7-28, 2013.

ARRUDA, Rinaldo Sérgio Vieira. Imagens do Índio: signos da intolerância. In: GRUPIONI, Luiz D. B.; VIDAL, Luz; FISCHMANN, Roseli (Orgs.). Povos indígenas e tolerância: construindo práticas de respeito e solidariedade. São Paulo: Editora Universidade de São Paulo, 2001, p. 43-61.

ARRUTI, José Maurício Adion. A emergência dos "remanescentes": notas para o diálogo entre indígenas e quilombolas. Mana, v.3, n. 2, p. 7-38, 1997.

BARTOLOMÉ, Miguel Alberto. As etnogêneses: velhos atores e novos papéis no cenário cultural e político. Mana, v. 12, n. 1, p. 39-68, 2006.

BECHARA, Evanildo. Minidicionário da língua portuguesa. Rio de Janeiro: Editora Novas Fronteiras, 2009.

BRASIL. [Constituição (1988)]. Constituição da República Federativa do Brasil de 1988. Brasília, DF: Presidência da República.

BRASIL. Supremo tribunal Federal (Pleno do Tribunal). Petição 3.388-4. Ação Popular. Demarcação da Terra Indígena Raposa Serra do Sol [...]. Rel. Carlos Britto, 19 mar. 2009.

BALDUS, Herbert. Akkulturation im Araguaya-Gebiet. Anthropos, n. 41, v. 44, p. 889891, 1949.

CARDOSO DE OLIVEIRA, Roberto. O movimento dos conceitos na antropologia. Revista de Antropologia, n. 36, p. 13-31, 1993.

CARNEIRO DA CUNHA, Manuela. Imagens de Índios do Brasil: século XVI. Estudos Avançados, n. 4, v. 10, set./dec. 1990.

CARNEIRO DA CUNHA, Manuela (Org.). História dos Índios no Brasil. São Paulo: Companhia das Letras, 1992.

CARNEIRO DA CUNHA. Cultura com aspas: e outros ensaios. São Paulo: Cosac Naify, 2009.

CARNEIRO DA CUNHA, Manuela. Índios no Brasil: história, direitos e cidadania. São Paulo: Claro Enigma, 2012.

CARNEIRO DA CUNHA, Manuela; BARBOSA, Samuel. Direito dos povos indígenas em disputa. São Paulo, Editora Unesp, 2018.

CARVALHO, Maria Rosário de. Os Pataxó de Barra Velha: seu subsistema econômico, Dissertação (Mestrado em Ciências Humanas) - Programa de Pós-Graduação em Ciências Humanas, Universidade Federal da Bahia, Salvador, 1977. 
CARVAlHO, Maria do Rosário G. A Identidade dos Povos do Nordeste. Anuário Antropológico, n. 82, p. 169-188, 1984.

COHN, Clarice. Cultura em transformação: os índios e a civilização. São Paulo Perspec., v. 15, n. 2, São Paulo, apr./jun. 2001.

CONKLIN, Beth a. Body Paint, Feathers, and VCRs: aesthetics and authenticity in Amazonian activism. American Ethnologist, n. 4, v. 24, nov. 1997, p. 711-737.

CRUZ, Leonardo de Oliveira. O "ser" e e "estar" índio: produção de identidades entre Kaingang e Krenak, em Vanuíre. 2007. Dissertação (mestrado em Ciências Sociais) Universidade Estadual Paulista Júlio de Mesquita Filho, São Paulo, 2007.

DIAS, Camila L.; CAPIBERIBE, Artionka. Os índios na constituição. São Paulo: Ateliê Editorial, 2019.

GALVÃO, Eduardo. Áreas culturais indígenas do Brasil; 1900-1959. Boletim do Museu Paraense Emílio Goeldi: Nova Série Antropologia, n. 8, p. 1-41, jan.1960

GEERTZ, Clifford. Interpretation of Cultures: Selected essays. New York (NY): Basic Books, 1973.

GEERTZ, Clifford. Local Knowledge: further essays in interpretative anthropology. New York (NY): Basic Books, 1983.

GEERTZ, Clifford. Works and Lives: The anthropologist as author. Stanford (CA): Stanford University Press, 1988.

GRAHAM, Laura R. How Should an Indian Speak? Amazonian Indians and the Symbolic Politics of Language in the Global Public Sphere. In: WARREN, Kay B.; JACKSON, Jean E. (Eds.) Indigenous Movements, Self-Representation, and the State in Latin America. Austin: University of Austin Press, 2003, p. 181-228.

GRAHAM, Laura R. Citando Mário Juruna: Imaginário linguístico e transformação da voz indígena na imprensa brasileira. Mana, Rio de Janeiro, v. 2, n. 17, p. 271-312, 2011.

HANDLER, Richard; LINNEKIN, Jocelyn. Tradition, Genuine or Spurious. The Journal of American Folklore, n. 385, v. 97, jun./sep. 1984, p. 273-290.

HARAWAY, Donna. Saberes localizados: a questão da ciência para o feminismo e o privilégio da perspectiva parcial. Cadernos PAGU, São Paulo, n. 5, p. 07-41, 1995.

HONNETH, Axel. A textura da Justiça: sobre os limites do procedimentalismo contemporâneo. Civitas, n. 3, v. 9, set./dez. 2009.

INGOLD, Tim. Editorial. Men, New series, n. 4, v. 27, dez. 1992, p. 693-696.

INSTITUTO BRASILEIRO DE GEOGRAFIA E ESTATÍSTICA. Censo demográfico 2010: população indígena. Rio de Janeiro: IBGE, 2010. Disponível em: 
https://censo2010.ibge.gov.br/noticias-

censo.html?busca $=1 \& \mathrm{id}=3 \&$ idnoticia $=2194 \& \mathrm{t}=$ censo-2010-populacao-indigena-896-9mil-tem-305-etnias-fala-274\&view=noticia. Acesso em: 10 jan. 2019.

KELLY, José Antônio. Notas para uma teoria do "virar Branco". Mana, v. 11, n. 1, p. 201-234, 2005.

KIRSCH, Stuart. Mining Capitalism: The relationship between corporations and their critics. Oakland (CA): University of California Press, 2014.

NASCIMENTO, Tiago Heliodoro. O direito em disputa: um etnografia da casa de Afonso Pena. 2017. Dissertação (mestrado em antropologia) - Faculdade de Filosofia e Ciência Humanas, Universidade Federal de Minas Gerais, Belo Horizonte, 2017.

MAIA, Arthur; PONTES, Giovani. Discurso: Colação 2018.02 (Direito). Belo Horizonte, Universidade Federal de Minas Gerais, 06 dez. 2018. (Comunicação oral).

MOL, Annemarie. Política ontológica. Algumas ideias e várias perguntas. In: NUNES, João A.; ROQUE, Ricardo. (Org.). Objetos impuros: experiências em estudos sociais e ciência. Porto: Edições Melhoramentos, 1999, p. 1-23.

OTERO DOS SANTOS, J. Sobre o virar índio: ritual e transformação entre os Arara. In: 29a Reunião de Antropologia Brasileira, 2014, Natal. 29a Reunião Brasileira de Antropologia. Brasília: ABA, 2014. v. 29. p. 111-150.

OLIVEIRA FILHO, João Pacheco de. Uma etnologia dos "índios misturados"? Situação colonial, territorialização e fluxos culturais. Mana, v. 4, n. 1, p. 47-77, 1998.

OLIVEIRA FILHO, João Pacheco de (Org.). A viagem da volta: etnicidade, política e reelaboração cultural no Nordeste indígena. Rio de Janeiro: Contra Capa Livraria, 1999.

PARAÍSO, Maria Hilda B. Os botocudos e sua trajetória história. In: CARNEIRO DA CUNHA, Manuela. (org.). História dos Í́ndios no Brasil. 2. ed. São Paulo: Companhia das Letras, 1992.

PEIRANO, Mariza. Etnografia não é método. Horizontes Antropológicos, v. 20, n. 42, p. 377-391, 2014.

REVISTA BRASILEIRA DE ESTUDOS POLÍTICOS. Apresentação. Revista Brasileira de Estudos Políticos, n. 40, sem paginação, 2012.

SAMPAIO, José Augusto Laranjeiras. De Caboclo a Índio: etnicidade e organização social e política entre os povos indígenas contemporâneos no Nordeste do Brasil; o Caso Kapinawá. Cadernos do Leme, n. 2, v. 3, 2011, p. 88- 191.

SAMPAIO-SILVA, Orlando. O Antropólogo Herbert Baldus. Revista de antropologia, n. 2, v. 43, 2000.

SPAEMANN, Robert. Persons: the difference between "someone" and "something". New York: Oxford University Press, 2006. 
STRATHERN, Marilyn. O Efeito Etnográfico. São Paulo: Cosac Naify, 2014.

SOARES, Geralda Chaves. Os Borun do Watú: os Índios do Rio Doce. Contagem: CEDEFES, 1992.

RIBEIRO, Darcy. Os Índios e a Civilização. Rio de Janeiro: Editora Civilização Brasileira, 1970.

SOUSA FILHO, Carlos F. M. de. O renascer dos povos indígenas para o direito. Curitiba: Juruá Editora, 1998.

SEEGER, Anthony; DAMATTA, Roberto, VIVEIROS DE CASTRO, Eduardo. A construção da pessoa nas sociedades indígenas brasileiras. Boletim do Museu Nacional, Nova Sério, Antropologia, Rio de Janeiro, n. 32, maio 1979.

SZTUTMAN, Renato. Apresentação. In: VIVEIROS DE CASTRO, Eduardo; SZTUTMAN, Renato (Orgs.). Eduardo Viveiros de Castro: Série Encontros. Rio de Janeiro: Azougue, 2008, p. 8-19.

TAYLOR, Charles. As Fontes do Self: A construção da identidade moderna. São Paulo: Loyola, 1997.

VILAÇA, Aparecida. O que significa tornar-se outro? Xamanismo e contato interétnico na Amazônia. RCBS, n. 44, v. 15, out. 2000.

VIVEIROS DE CASTRO, Eduardo. A inconstância da alma selvagem. São Paulo: Cosac Naify, 2002.

VIVEIROS DE CASTRO, Eduardo. O nativo relativo. Mana, Rio de Janeiro, v. 8, n. 1, p. 113-148, abr. 2002.

VIVEIROS DE CASTRO, Eduardo; SZTUTMAN, Renato (Orgs.). Eduardo Viveiros de Castro: Série Encontros. Rio de Janeiro: Azougue, 2008.

VIVEIROS DE CASTRO, Eduardo. Metafísicas Canibais. São Paulo: Cosac Naify, 2015.

VIVEIROS DE CASTRO, Eduardo. Os involuntários da Pátria. ARAC $\hat{\mathbf{E}}$ - Direitos Humanos em Revista, n. 5, fev. 2017.

WAGNER, Roy. The invention of culture. Chicago: The university of Chicago Press, 1981.

WARAT, Luís Alberto. Senso crítico e senso comum teórico dos juristas. Sequência, v. 3, n. 5, 1982.

WERNECK, Gustavo. Escola de líderes e de excelência na área do direito comemora aniversário em BH. Estado de Minas, Gerais, 27 de out. de 2012. 
Recebido em: 27/05/2020 * Aprovado em: 16/09/2020 * Publicado em: 16/12/2020 